\title{
Stimulation of the final cell cycle in the stomatal lineage by the cyclin CYCD7;1 under regulation of the MYB transcription factor FOUR-LIPS
}

Running Title: CYCD7;1 stimulated stomata formation

Farah Patell ${ }^{1,4}$, David Newman ${ }^{1}$, EunKyoung Lee ${ }^{2}$, Zidian $\mathrm{Xie}^{3,5}$, Carl Collins ${ }^{4,6}$, Erich Grotewold $^{3}$, James A.H. Murray ${ }^{1,4^{*}}$ and Walter Dewitte ${ }^{1,4^{*}}$

${ }^{1}$ Cardiff School of Biosciences, Cardiff University, CF10 3AX, Wales, United Kingdom

${ }^{2}$ Department of Botany, University of British Columbia, Vancouver, British Columbia V6T 1Z4, Canada

3 Department of Biochemistry and Molecular Biology, Michigan State University, East Lansing, Michigan, 48824, USA

${ }^{4}$ Institute of Biotechnology, University of Cambridge, CB2 1QT, UK

${ }^{5}$ Present address: Department of Molecular Biosciences and Bioengineering, University of Hawaii, Honolulu, HI 968222, USA

${ }^{6}$ Present address: Skylab Bio Ltd., Kent, CT13 9FF, UK

\section{Corresponding authors:}

Walter Dewitte and Jim Murray, Cardiff School of Biosciences, Cardiff University, The Sir Martin Evans Building, Museum Avenue, Cardiff, CF10 3AX, Tel: 44 (0) 2920874190, email: DewitteW@cardiff.ac.uk and Murrayja1@cardiff.ac.uk

Key words: stomata, cell division, epidermis, cyclin, Arabidopsis thaliana 


\section{Summary Statement}

The formation of paired guard cells in the epidermis of the Arabidopsis thaliana shoot, requires the activity of the D-type cyclin CYCD7;1 for the normal timing of the final division.

\section{Abstract (180 words)}

Stomatal guard cells are formed through a sequence of asymmetric and symmetric divisions in the epidermis of the sporophyte of most land plants. We show that several D-type cyclins are consecutively activated in the stomatal linage in the epidermis of Arabidopsis thaliana. Whereas CYCD2;1 and CYCD3;2 are activated in the meristemoids early in the lineage, CYCD7;1 is activated before the final division. CYCD7;1 expression peaks in the guard mother cell, where its transcription is modulated by the FOUR-LIPS/MYB88 transcription factor. FOUR-LIPS/MYB88 interacts with the CYCD7;1 promoter and represses CYCD7;1 transcription. $C Y C D 7 ; 1$ stimulates the final symmetric division in the stomatal lineage, since guard cell formation is delayed in the cycd7;1 mutant epidermis and guard mother cell (GMC) divisions in four-lips mutant guard mother cells are limited by loss of function of CYCD7;1. Hence, the precise activation of a specific D-type cyclin, CYCD7;1, is required for correct timing of the last symmetric division that creates the stomatal guards cells, and CYCD7;1 expression is regulated by the FLP/MYB pathway that ensures cell cycle arrest in the stomatal guard cells. 
bioRxiv preprint doi: https://doi org/10.1101/207845 this version posted October 23, 2017. The copyright holder for this preprint (which was not certified by peer review) is the author/funder, who has granted bioRxiv a license to display the preprint in perpetuity. It is made available under aCC-BY-NC-ND 4.0 International license. 


\section{INTRODUCTION}

Stomata are micro-valves in the epidermis of the shoot that mediate gas exchange between internal tissues and the atmosphere and consist of two specialized sister guard cells (GCs) surrounding a pore. The evolution of stomata is associated with the colonization of land by early plants (Vaten and Bergmann, 2012). In Arabidopsis, the stomatal lineage arises from stem cell-like meristemoid mother cells (Pillitteri and Torii, 2012), which divide asymmetrically to form a meristemoid (M) that develops into an ovoid guard mother cell (GMC). Finally GMCs divide symmetrically, and the daughters differentiate into the two GCs bordering the stomatal pore.

CDK activity regulates progression through the mitotic cell cycle. In addition to the canonical conserved CDK homologous to yeast cdc2+/CDC28 and mammalian CDK1, which is called CDKA in plants, plants encode an additional unique type of CDK known as CDKB. Plant cyclins are represented by three major groups, A-, B- and D-types (De Veylder et al., 2007). In the stomatal lineage, the symmetric GMC division requires the cyclin-dependent kinase CDKB1;1 and cyclin CYCA2 (Boudolf et al., 2004; Vanneste et al., 2011), after which GCs stop further cell cycle progression, reportedly with a DNA content of $2 \mathrm{C}$ indicative of $\mathrm{G} 1$ arrest (Melaragno et al., 1993). FOUR-LIPS (FLP) and the closely related gene MYB88 are required to prevent multiple symmetric divisions of the GMC through direct regulation of multiple cell cycle-related genes (Xie et al., 2010).

Cyclin D (CYCD)-CDK complexes have a primary role in regulating the G1/S transition through control of RETINOBLASTOMA-RELATED (RBR) protein activity and thereby the activity of various E2F factor complexes (Magyar et al., 2012; Menges et al., 2006; Zhao et al., 2012). In higher plants, the different CYCDs can be classified into six conserved subgroups (Menges et al., 2007), and there is accumulating evidence for distinct developmental roles for different CYCD subgroups (Dewitte et al., 2007; Nieuwland et al., 2009; Sanz et al., 2011; Sozzani et al., 2010). Whilst $R B R$ has been shown to have a role in regulating asymmetric divisions of the stomatal lineage (Weimer et al., 2012), the role of CYCDs as regulators of RBR function in this process has not been investigated. Here we show that $C Y C D 7 ; 1$ is under control of the FLP/MYB88 transcription factors and stimulates the terminal division of the GMC.

\section{RESULTS AND DISCUSSION}

\section{CYCD expression in the stomatal lineage}

Given the rate limiting role of several CYCD genes in proliferation of plant tissues (Dewitte et 
al., 2007), we examined the expression of $C Y C D$ genes in the stomatal lineage of the Arabidopsis shoot with the exception of $C Y C D 4 ; 2$ and $C Y C D 5 ; 1$. Only CYCD2;1, CYCD3;2 and CYCD7;1 reporters showed activity (Fig. 1). CYCD3;2 expression was activated in meristemoids and gradually declined in GMCs and GCs, becoming undetectable in mature GCs (mGCs; Fig. 1B). CYCD2;1 pro::CYCD2;1-GFP fluorescence was detected throughout the later lineage in nuclei of meristemoids, GMCs, and young GCs (Fig. 1A). In line with this, the available ATH1 GeneChip data of the stomatal lineage suggest the presence of CYCD2;1 transcripts throughout the different phases of the stomatal development and a maximum of $C Y C D 3 ; 2$ expression in meristemoids (eFP browser, data source Guard Cell).

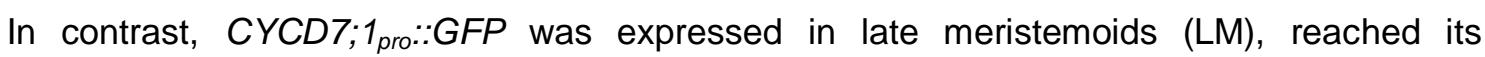
maximum in GMCs, persisted until after the symmetric division and declined as GCs matured. The GFP signal of a fusion protein transgene consisting of the $C Y C D 7 ; 1$ promoter and genomic coding region fused to eGFP was relatively weak, and gave strongest detectable signal in LM and early GMC nuclei (Fig. 1C-D), perhaps due to destabilisation of eGFP as a result of fusion to CYCD7;1. This expression pattern was consistent in stomatal lineages in the cotyledon, leaf and stem epidermis (Fig. 1E-F). Interestingly, CYCD7;1 expression as determined by both the transcriptional reporter and translational $C Y C D 7 ; 1$ GFP fusion gene was not detected in sporophytic tissue outside the stomatal lineage, although it was observed in the sperm cells of pollen. Given that $C Y C D 7 ; 1$ is not represented on the ATH1 chip, our current knowledge on CYCD7;1 expression is still fragmented, but these specific expression dynamics of CYCD2;1, CYCD3;2 and CYCD7;1 are in agreement with the transcript levels in the stomatal lineage detected by Adrian et al, 2015. Nevertheless, we cannot exclude expression of $C Y C D 7 ; 1$ elsewhere under different experimental conditions. These observations suggested roles for $C Y C D 2 ; 1, C Y C D 3 ; 2$ and particularly $C Y C D 7 ; 1$ in the final phases of stomatal development.

\section{CYCD7;1 is transcriptionally controlled by FLP/ MYB88}

FOUR LIPS (FLP) and its close relative MYB88 limit GMC division by directly regulating multiple cell cycle genes (Xie et al., 2010), and in flp mutants GMC daughter cells reiterate the symmetric division program generating linear clusters of GCs. FLP is activated in late GMCs (Xie et al., 2010) coinciding with the timing of reduced CYCD7;1-GFP fluorescence (Fig. 1D). These observations suggested that FLP/MYB88 could negatively regulate CYCD7;1, so we examined CYCD7;1 mRNA levels in a strong flp allele and in the double flp myb88 mutant (Fig. 2A). To compensate for possible differential contribution of cell types in each background, $C Y C D 7 ; 1$ transcript levels were normalized against genes that are (1) either ubiquitously expressed (ACTIN2), (2) specific for GMCs and young GCs (FAMA), or 
(3) for mature GCs (KAT1). CYCD7;1 mRNA levels were elevated in both flp and flp myb88 mutants (Lai et al., 2005), regardless of normalization (Fig. 2A). Consistent with the proposed negative regulation of $C Y C D 7 ; 1$ by FLP, we observed elevated $C Y C D 7 ; 1$ pro:::GFP fluorescence in flp GMCs (Fig. 2B-C).

We next determined whether FLP/MYB88 binds to the CYCD7;1 promoter using chromatin immunoprecipitation. An anti-FLP/MYB88 antiserum immunoprecipitated a CYCD7;1 promoter fragment in WT, but not in flp myb88 control extracts (Fig. 2D,E). We conclude that in the GMC, $C Y C D 7 ; 1$ expression is negatively regulated by FLP/MYB88 binding.

\section{CYCD7;1 stimulates proliferation of the GMC}

In order to understand CYCD7;1 action in the proliferating GMC, we identified a loss-offunction insertion allele $c y c d 7 ; 1-1$. First we monitored the populations of stomatal precursors and stomata in the WT and cycd7;1-1 abaxial epidermis of cotelydons over a time course of 14 days, from germination onwards (Fig. 3D), and detected an increased number of stomatal precursors, both meristemoids and GMCs, at 7 days after germination (7DAG) and 10DAG in cycd7;1-1, associated with a reduction of the number of stomata formed by these

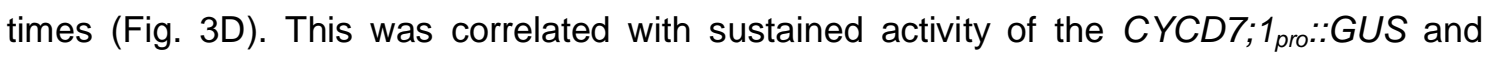
CDKB1;1 pro::GUS (Boudolf et al., 2005) reporters in the cycd7;1-1 epidermis (Fig. 3C). These markers are normally expressed in both mutant and WT GMC (Fig. 3A,B), and so these observations are consistent with a transitory accumulation of GMCs in developing cycd7;1-1 cotyledons. This suggested a delay in progression through the cell cycle leading to the terminal GMC division, and in order to pinpoint CYCD7;1 action we monitored nuclear size as a proxy for cell cycle progression. Whilst meristemoids have a similar average nuclear size as a population of unexpanded epidermal pavement cells, we observed a gradual increase in nuclear size as cells transit from meristemoids to guard mother cells, indicating that GMC differentiation is associated with cell cycle progression. While the meristemoids nucleus increases in size prior to the bulging associated with GMC differentiation, nuclear enlargement is slower in $c y c d 7 ; 1-1$ mutants suggesting a delay early on in cell cycle progression, in line with the observed larger proportion of both meristemoids and GMCs in the mutant's epidermis (Fig. 4A).

Over time, a large proportion of flp mutant GCs reiterates the GMC program of symmetric division, resulting in clusters with up to 8 cells after 14 days. We observed that CYCD7; 1 expression is re-activated in these proliferating flp stomatal clusters (Fig. 4B) consistent with a reiteration of GMC fate. Loss of $C Y C D 7 ; 1$ function reduces the number of divisions of flp GMCs in the flp cycd7;1-1 mutant combination (Fig. 4C). Taken together, we conclude that 
CYCD7;1 stimulates the cell cycle progression required for GMC division, and that its levels are moderated in the developed GMC by the FLP/MYB88 transcription factor.

\section{Discussion}

The formation of stomatal guard cells in the epidermis is tightly coordinated during organ growth, and requires accurate coordination of fate acquisition and cell division. Besides from generating the essential guard cells that flank and control the opening of the micropores in the epidermis, the stomatal lineage generates a large proportion of pavement cells by asymmetric divisions of meristemoids and ground lineage cells. In contrast to the asymmetric division of meristemoids, the GMC undergoes a single symmetric division upon which the newly formed guard cells become quiescent, ensuring only two cells flank the pore (Bergmann and Sack, 2007). We observed that the differentiation of a meristemoid into a bulged GMCs is accompanied with the enlargement of the nucleus, suggestive of S-phase progression. After division of the GMC, the FLP/MYB88 transcription factor limit re-entry of guard cells into a subsequent cell cycle by targeting genes encoding for core cell cycle regulators. Here we demonstrate that the CYCD7;1 gene, encoding for a D-type cyclin expressed in the guard cell precursor, is another FLP/MYB88 target. As the loss of function phenotype for the entire $C Y C D$ gene family in a higher plants has not been reported, it is still unclear whether or not D-type cyclins are essential for cell cycle progression. Nevertheless, CYCDs are rate limiting for cell cycle entry in somatic tissues (Dewitte et al., 2003; Dewitte et al., 2007; Sozzani et al., 2010), as well as pathogen induced cell division (Stes et al., 2011), supporting their function in cell cycle stimulation. Our observations indicate that CYCD7;1 stimulates the final division in the stomatal lineage and its expression is restricted by the FLP/MYB88 transcription factor .

Here we show that the transcription of different D-type cyclin encoding genes is consecutively activated in the stomatal lineage, in line with the available transcriptomics data (Adrian et al., 2015), suggesting that they are targets for pathways that mediate the different fate transitions. The Retinoblastoma-related protein (RBR), a substrate of D-type cyclin/CDK kinase complexes, interacts with FAMA, FLP and MYB88 to ensure terminal differentiation (Lee et al., 2014; Matos et al., 2014) of guard cells. RBR interacts with several transcription factors in other systems as well, and the activity of D-type cyclins is integrated in RBR mediated feedback circuits (Cruz-Ramirez et al., 2012; Sozzani et al., 2010). Now the question arises if the consecutive action of these CYCDs in the different cell types of stomatal lineage regulates the activity of the RBR interacting transcription factors by tuning the interaction with RBR. 
Furthermore levels of CYCD could regulate the division potential of the different cell types. In this respect, the observation that $C Y C D 3 ; 2$ is a key target of the PEAPOD containing repressor complex is intriguing (Gonzalez et al., 2015).

We found that CYCD7;1 is a target of the FLP/MYB88 transcription factor, which suppress CYCD7; 1 transcription, which together with the already identified targets involved in S-phase and mitosis (Xie et al., 2010) cements the function of FLP/MYB88 as an essential transcriptional repressor of core cell cycle genes for correct morphogenesis of stomata. Our observations suggest that CYCD7;1 increases the rate of cell cycle progression before the final mitosis of the GMC, in order to ensure GCs are formed timely.

\section{MATERIAL AND METHODS}

Plant Material

The cycd7;1-1 (INRA-FCC172) insert line was initially generated in the Ws ecotype and has a T-DNA insertion in the second intron of CYCD7;1, corresponding to 715 bp downstream of the transcription start site. The allele was crosses twice into Col-0 and the absence of fulllength CYCD7;1 transcripts was confirmed by qRT-PCR using a primer set that spans the insertion site, and a primer set targeting the sequence downstream of the insertion and the levels were reduced to less than $1 \%$ of wild-type level in both cases. CYCDpro::GFP and CYCD7;1pro::CYCD7;1-GFP constructs were made by gateway technology and introduced into Col-O by floral dipping (Collins et al., 2012; Sanz et al., 2011). Primers are listed in supplementary table $\mathrm{S} 1$.

\section{Microscopy}

Differential interference contrast light microscopy (Zeiss Imager M1) of cleared tissues was used for epidermal analysis (De Veylder et al., 2001). Confocal microscopy was performed on whole mount preparations using a Zeiss 510 or 710 Meta confocal laser-scanning microscope. Cell walls were stained 1-2 mins with propidium iodide (100ug/ml, Molecular Probes).

RNA isolation and relative transcript quantification 
Relative quantification using real-time qPCR was performed using ACTIN, KAT1 and FAMA as reference genes for normalization (Lai et al., 2005). Gene specific primers are listed (Table S1).

\section{ChIP of FLP/MYB88 target sequences}

Antibodies against the FLP/MYB88 proteins were generated by inoculating rabbits with NiNTA-affinity purified $\mathrm{NHis}_{6}-\mathrm{MYB88}$. ChIP experiments were performed as described (Morohashi et al., 2007; Xie and Grotewold, 2008), with modifications. Ten-day old seedlings of wild type, flp-1 myb88 (200 mg fresh weight for each) were cross-linked in 1\% formaldehyde for 20 minutes by vacuum filtration, and the cross-linking reaction was stopped by the addition of $0.1 \mathrm{M}$ glycine (final concentration). Tissues were ground fine using mortar and pestle in liquid nitrogen and then suspended in $300 \mu \mathrm{l}$ of lysis buffer $(50 \mathrm{mM}$ HEPES, pH7.5; 150 mM NaCl; 1 mM EDTA, pH8.0; 1\% Triton X-100; 0.1\% sodium deoxycholate; $0.1 \%$ SDS; $1 \mathrm{mM}$ phenylmethanesulphonylfluoride [PMSF]); $10 \mathrm{mM}$ sodium butyrate; $1 \mathrm{X}$ protein protease inhibitor Sigma), and sonicated to achieve a DNA size of 0.3 $1 \mathrm{~kb}$. The sonication conditions using the Bioruptor (Diagenode) were as follows: At high power; $30 \mathrm{sec}$ sonication followed by $30 \mathrm{sec}$ break; change ice every ten minutes; 30 minutes in total. After clearing using $30 \mu \mathrm{l}$ salmon sperm DNA/protein-A agarose (Upstate) at $4^{\circ} \mathrm{C}$ for at least one hour, the supernatant fractions were incubated with $1 \mu \mathrm{l} \mathrm{FLP/MYB88}$ rabbit polyclonal antibody at $4{ }^{\circ} \mathrm{C}$ overnight. At the same time, $10 \%$ of the supernatant was saved as the input fraction. The chromatin-antibody complex was incubated with salmon sperm DNA/protein-A agarose (Upstate) at $4^{0} \mathrm{C}$ for at least 3 hours, washed with lysis buffer, LNDET buffer (0.25 M lithium chloride; $1 \%$ NP40; $1 \%$ sodium deoxycholate and $1 \mathrm{mM}$ EDTA, pH8.0) and TE buffer (10 mM Tris-Cl, pH7.5; 1 mM EDTA, pH8.0) twice respectively, and the complex was reverse cross-linked in elution buffer (1\% SDS; $0.1 \mathrm{M} \mathrm{NaHCO}_{3} ; 1$ $\mathrm{mg} / \mathrm{ml}$ proteinase $\mathrm{K}$ ) overnight at $65^{\circ} \mathrm{C}$. DNA was extracted using the PCR Cleaning Kit (Qiagen). Three biological replicates have been conducted. The ChIP-qPCR primers used for CYCD7;1 were CYCD7;1-qP-F: 5'- AGAATGCATTTACCGCGTTT -3' and CYCD7;1-qPR: 5'- AAAGAAAATATGGAAGCGAGGA -3', for PDF2 were PDF2-F: 5'GACGATTCTTCGTGCAGTATCGCTT -3' and PDF2-R: 5'GATACGGCCATGCTTGGTGGAGCTA -3'.

\section{Measurement of nuclear maximum cross-sectional area}

Seedlings were fixed and DNA was stained in Vectashield solution with 4',6'-diamindino-2phenylindole (Vector Laboratories, Burlingame, CA). The GCs were examined by confocal 
microscopy (Zeiss meta 710). In the optical section with the largest nuclear area, the nuclear outline was traced and the MSA and average fluorescence was scored.

Statistical tests

Due to lack of normality, non-parametric two-tailed Mann-Whitney $U$ tests were employed.

\section{Acknowledgements}

The authors wish to acknowledge the invaluable help from Fred Sack. We thank A. Marchbank, S. Howroyd, J. Kilby and G. Aletti for technical assistance, S. Scofield for help and discussions.

\section{Competing interests}

No competing interests declared

\section{Funding}

FP: Cambridge Nehru Trust; EG: NSF-MCB-0418891; ZX: Predoctoral Excellence in Plant Molecular Biology and Biotechnology fellowship; JM/WD: BBSRC grants BB/E022383, BB/D011914 and ERASysBio+ initiative under the EU ERA-NET+ scheme in FP7; FS: Natural Sciences and Engineering Research Council grant PG 22R92904. 
References

Adrian, J., Chang, J., Ballenger, C. E., Bargmann, B. O., Alassimone, J., Davies, K. A., Lau, O. S., Matos, J. L., Hachez, C., Lanctot, A., et al. (2015). Transcriptome dynamics of the stomatal lineage: birth, amplification, and termination of a self-renewing population. Developmental cell 33, 107-118.

Bergmann, D. C. and Sack, F. D. (2007). Stomatal development. Annual review of plant biology 58, 163-181.

Boudolf, V., Barroco, R., Engler Jde, A., Verkest, A., Beeckman, T., Naudts, M., Inze, D. and De Veylder, L. (2004). B1-type cyclin-dependent kinases are essential for the formation of stomatal complexes in Arabidopsis thaliana. The Plant cell 16, 945-955.

Collins, C., Dewitte, W. and Murray, J. A. (2012). D-type cyclins control cell division and developmental rate during Arabidopsis seed development. Journal of experimental botany 63, 3571-3586.

Cruz-Ramirez, A., Diaz-Trivino, S., Blilou, I., Grieneisen, V. A., Sozzani, R., Zamioudis, C., Miskolczi, P., Nieuwland, J., Benjamins, R., Dhonukshe, P., et al. (2012). A bistable circuit involving SCARECROWRETINOBLASTOMA integrates cues to inform asymmetric stem cell division. Cell 150, 1002-1015.

De Veylder, L., Beeckman, T., Beemster, G. T., Krols, L., Terras, F., Landrieu, I., van der Schueren, E., Maes, S., Naudts, M. and Inze, D. (2001). Functional analysis of cyclin-dependent kinase inhibitors of Arabidopsis. The Plant cell 13, 1653-1668.

De Veylder, L., Beeckman, T. and Inze, D. (2007). The ins and outs of the plant cell cycle. Nature reviews. Molecular cell biology 8, 655-665.

Dewitte, W., Riou-Khamlichi, C., Scofield, S., Healy, J. M., Jacqmard, A., Kilby, N. J. and Murray, J. A. (2003). Altered cell cycle distribution, hyperplasia, and inhibited differentiation in Arabidopsis caused by the D-type cyclin CYCD3. The Plant cell 15, 79-92.

Dewitte, W., Scofield, S., Alcasabas, A. A., Maughan, S. C., Menges, M., Braun, N., Collins, C., Nieuwland, J., Prinsen, E., Sundaresan, V., et al. (2007). Arabidopsis CYCD3 D-type cyclins link cell proliferation and endocycles and are rate-limiting for cytokinin responses. Proc Natl Acad Sci U $S$ A 104, 14537-14542.

Gonzalez, N., Pauwels, L., Baekelandt, A., De Milde, L., Van Leene, J., Besbrugge, N., Heyndrickx, K. S., Cuellar Perez, A., Durand, A. N., De Clercq, R., et al. (2015). A Repressor Protein Complex Regulates Leaf Growth in Arabidopsis. The Plant cell 27, 2273-2287.

Lai, L. B., Nadeau, J. A., Lucas, J., Lee, E. K., Nakagawa, T., Zhao, L., Geisler, M. and Sack, F. D. (2005). The Arabidopsis R2R3 MYB proteins FOUR LIPS and MYB88 restrict divisions late in the stomatal cell lineage. The Plant cell 17, 2754-2767.

Lee, E., Lucas, J. R. and Sack, F. D. (2014). Deep functional redundancy between FAMA and FOUR LIPS in stomatal development. Plant J 78, 555-565.

Magyar, Z., Horvath, B., Khan, S., Mohammed, B., Henriques, R., De Veylder, L., Bako, L., Scheres, B. and Bogre, L. (2012). Arabidopsis E2FA stimulates proliferation and endocycle separately through RBR-bound and RBR-free complexes. The EMBO journal 31, 1480-1493. 
Matos, J. L., Lau, O. S., Hachez, C., Cruz-Ramirez, A., Scheres, B. and Bergmann, D. C. (2014). Irreversible fate commitment in the Arabidopsis stomatal lineage requires a FAMA and RETINOBLASTOMA-RELATED module. eLife 3.

Melaragno, J. E., Mehrotra, B. and Coleman, A. W. (1993). Relationship between Endopolyploidy and Cell Size in Epidermal Tissue of Arabidopsis. The Plant cell 5, 1661-1668.

Menges, M., Pavesi, G., Morandini, P., Bogre, L. and Murray, J. A. (2007). Genomic organization and evolutionary conservation of plant D-type cyclins. Plant physiology 145, 1558-1576.

Menges, M., Samland, A. K., Planchais, S. and Murray, J. A. (2006). The D-type cyclin CYCD3;1 is limiting for the G1-to-S-phase transition in Arabidopsis. The Plant cell 18, 893-906.

Morohashi, K., Zhao, M., Yang, M., Read, B., Lloyd, A., Lamb, R. and Grotewold, E. (2007). Participation of the Arabidopsis bHLH factor GL3 in trichome initiation regulatory events. Plant Physiol 145, 736-746.

Nieuwland, J., Maughan, S., Dewitte, W., Scofield, S., Sanz, L. and Murray, J. A. (2009). The D-type cyclin CYCD4;1 modulates lateral root density in Arabidopsis by affecting the basal meristem region. Proc Natl Acad Sci U S A 106, 22528-22533.

Pillitteri, L. J. and Torii, K. U. (2012). Mechanisms of stomatal development. Annual review of plant biology 63, 591-614.

Sanz, L., Dewitte, W., Forzani, C., Patell, F., Nieuwland, J., Wen, B., Quelhas, P., De Jager, S., Titmus, C., Campilho, A., et al. (2011). The Arabidopsis Dtype cyclin CYCD2;1 and the inhibitor ICK2/KRP2 modulate auxin-induced lateral root formation. The Plant cell 23, 641-660.

Sozzani, R., Cui, H., Moreno-Risueno, M. A., Busch, W., Van Norman, J. M., Vernoux, T., Brady, S. M., Dewitte, W., Murray, J. A. and Benfey, P. N. (2010). Spatiotemporal regulation of cell-cycle genes by SHORTROOT links patterning and growth. Nature 466, 128-132.

Stes, E., Biondi, S., Holsters, M. and Vereecke, D. (2011). Bacterial and plant signal integration via D3-type cyclins enhances symptom development in the Arabidopsis-Rhodococcus fascians interaction. Plant physiology 156, 712 725.

Vanneste, S., Coppens, F., Lee, E., Donner, T. J., Xie, Z., Van Isterdael, G., Dhondt, S., De Winter, F., De Rybel, B., Vuylsteke, M., et al. (2011). Developmental regulation of CYCA2s contributes to tissue-specific proliferation in Arabidopsis. The EMBO journal 30, 3430-3441.

Vaten, A. and Bergmann, D. C. (2012). Mechanisms of stomatal development: an evolutionary view. EvoDevo 3, 11.

Weimer, A. K., Nowack, M. K., Bouyer, D., Zhao, X., Harashima, H., Naseer, S., De Winter, F., Dissmeyer, N., Geldner, N. and Schnittger, A. (2012). Retinoblastoma related1 regulates asymmetric cell divisions in Arabidopsis. The Plant cell 24, 4083-4095.

Xie, Z. and Grotewold, E. (2008). Serial ChIP as a tool to investigate the colocalization or exclusion of proteins on plant genes. Plant methods 4, 25.

Xie, Z., Lee, E., Lucas, J. R., Morohashi, K., Li, D., Murray, J. A., Sack, F. D. and Grotewold, E. (2010). Regulation of cell proliferation in the stomatal lineage by the Arabidopsis MYB FOUR LIPS via direct targeting of core cell cycle genes. The Plant cell 22, 2306-2321. 
bioRxiv preprint doi: https://doi.org/10.1101/207845; this version posted October 23, 2017. The copyright holder for this preprint (which was not certified by peer review) is the author/funder, who has granted bioRxiv a license to display the preprint in perpetuity. It is made available under aCC-BY-NC-ND 4.0 International license.

Zhao, X., Harashima, H., Dissmeyer, N., Pusch, S., Weimer, A. K., Bramsiepe, J., Bouyer, D., Rademacher, S., Nowack, M. K., Novak, B., et al. (2012). A general G1/S-phase cell-cycle control module in the flowering plant Arabidopsis thaliana. PLoS genetics 8, e1002847. 


\section{Figure legends}

Figure 1. $C Y C D$ expression in the stomatal lineage. (A) Expression of CYCD2;1;pro::CYCD2;1-GFP, (B) CYCD3;2pro::GFP, (C) CYCD7;1pro::GFP, (D) CYCD7;1pro::CYCD7;1-GFP in M (meristemoid), LM (late meristemoid), eGMC (early GMC), LGMC (late GMC), *GC (recently formed GC pair), yGC (young GC pair) and mGC (mature GC). (E) and (F). CYCD7;1pro::GFP expression in leaf epidermis showing expression in eGMCs, LGMCs and *GCs

Figure 2. FLP moderates $C Y C D 7 ; 1$ transcription (A) Expression of $C Y C D 7 ; 1$ determined by qRT-PCR in WT, flp-7 and flp-1 myb88 normalised to ACTIN2 (blue), FAMA (green) or KAT1 (yellow). (B) Expression of CYCD7;1pro::GFP reporter in WT and flp-7 mutant (C) Quantification of CYCD7;1pro::GFP fluorescence in WT and flp-7 GMCs in cotelydons and leaves. (D) PCR amplification of immunoprecipitated chromatin (ChIP) using control serum (left) and FLP/MYB antiserum (right) from WT and flp-1 myb88 leaves. Top rows: PCR using CYCD7;1pro primers; bottom rows ACTIN2/7pro primers. Sequential dilutions from left to right. Note ChIP band only in WT extract using CYCD7;1pro primers (top right). (E) Quantification of ChIP of control (PDF2) and CYCD7;1 promoter fragments in WT (blue) and flp-1 myb88 (grey).

Figure 3. CYCD7;1 is rate limiting for the formation of stomata. (A-B) The expression window of the $p C Y C D 7 ; 1:: G U S-G F P$ and $p C D K B 1 ; 1:: G U S$ markers is unaltered in the cycd7;1-1 epidermis. (C) The expression of both markers persists longer in the cycd7;1-1 epidermis. (D) Quantification of stomatal cell types in the abaxial epidermis of WT and cycd7;1-1 epidermis over time reveals a prolonged presence of stomatal precursors in the mutant. The total number for each stomatal cell type in the abaxial epidermis of the cotelydon is listed.

Figure 4. CYCD7;1 is rate limiting for the division of the stomatal precursor. (A) Specialisation of meristemoids into GMC is associated with nuclear enlargement. WT nuclei increase in size, reflected by the maximum surface area of a cross section (MSA) when meristemoids cells adopt the GMC morphology, a process delayed in the cycd7;1-1 epidermis. Insert histogram depicts MSA in a population of hexagonal undifferentiated pavement cells in a young leaf $\left(<2 \mathrm{~mm}^{2}\right)$. (B,C) Loss of $C Y C D 7 ; 1$ function, normally reactivated in proliferating flp GMCs (B), reduces the number of cells in flp stomatal clusters (C). 
bioRxiv preprint doi: https://doi org/10.1101/207845. this version posted October 23, 2017. The copyright holder for this preprint (which was not certified by peer review) is the author/funder, who has granted bioRxiv a license to display the preprint in perpetuity. It is made available under aCC-BY-NC-ND 4.0 International license. 


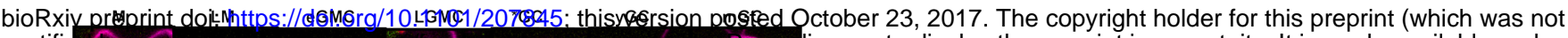

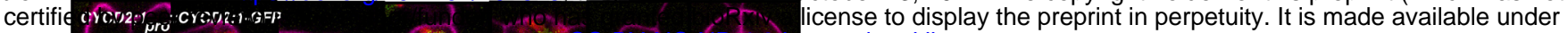

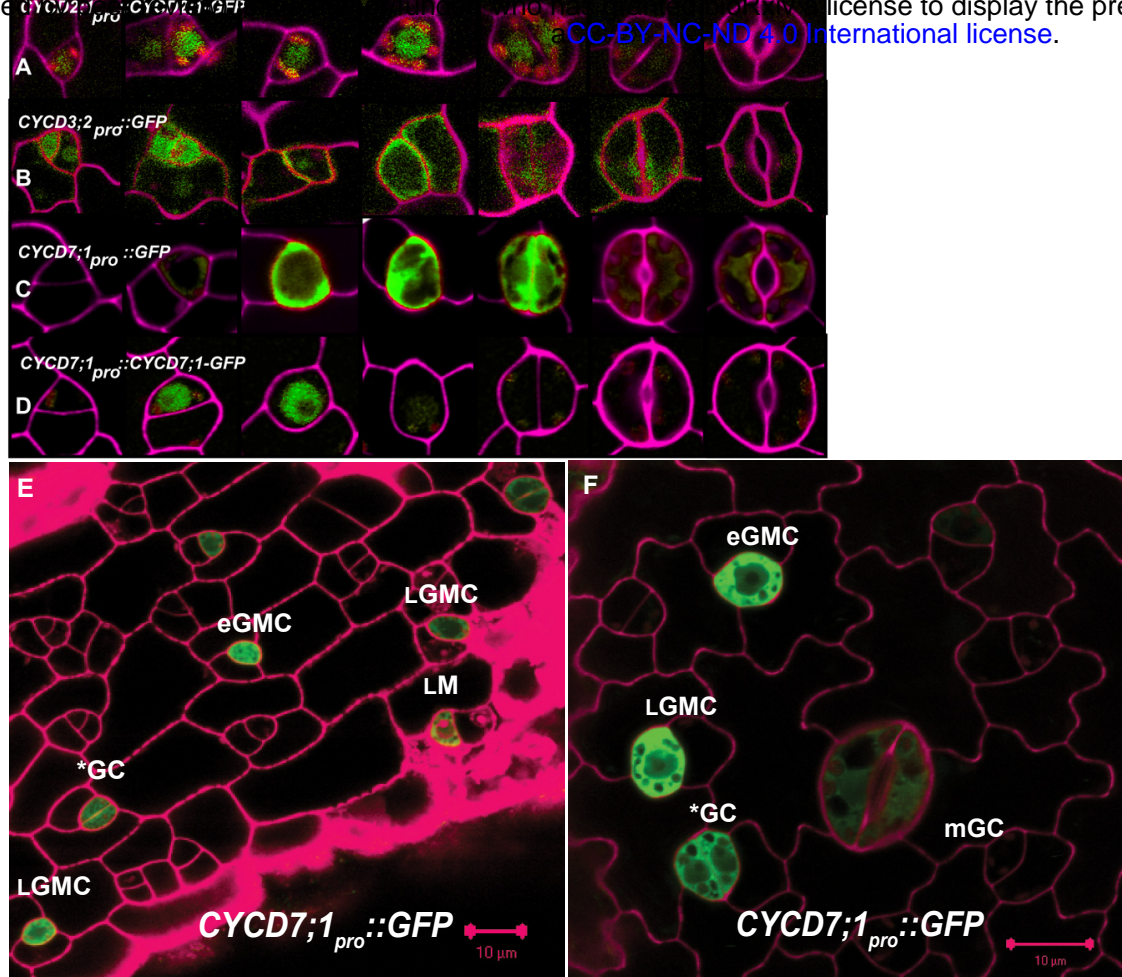

Figure 1 
<smiles>C[Si]#[Si]</smiles> 
A

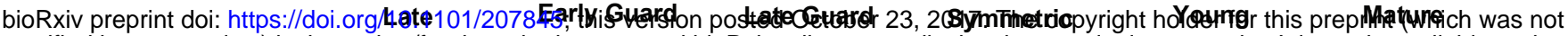

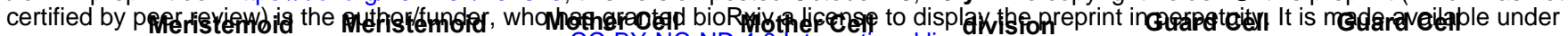

(M)

(LM)

aCeG-BY-NC-ND 4.0 (LGMC)

(yGC)

(mGC)

CYCD7;1 ::GUS-GFP

pro

cycd7;1-1

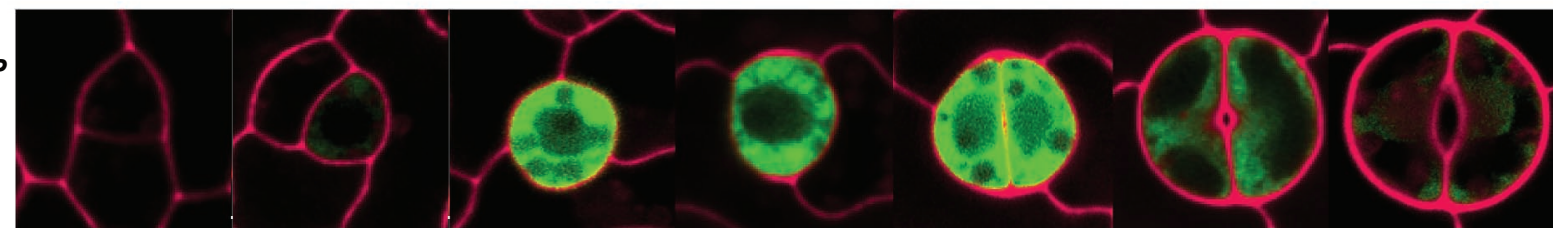

CYCD7;1 ::GUS-GFP

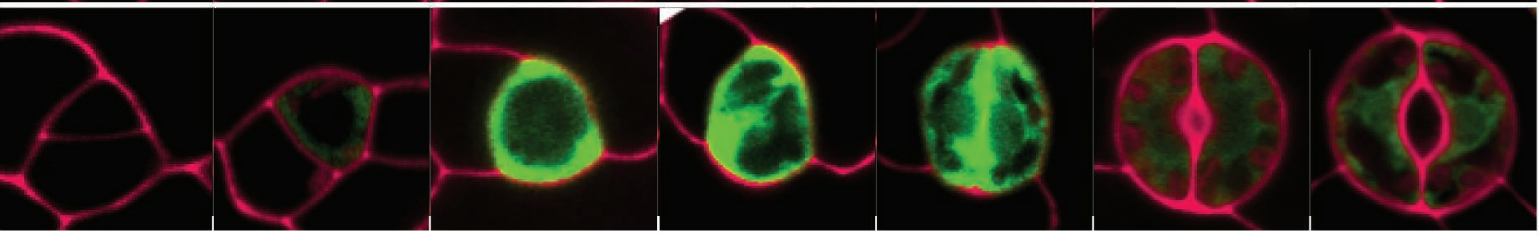

B

CDKB1; 1 pro ::GUS

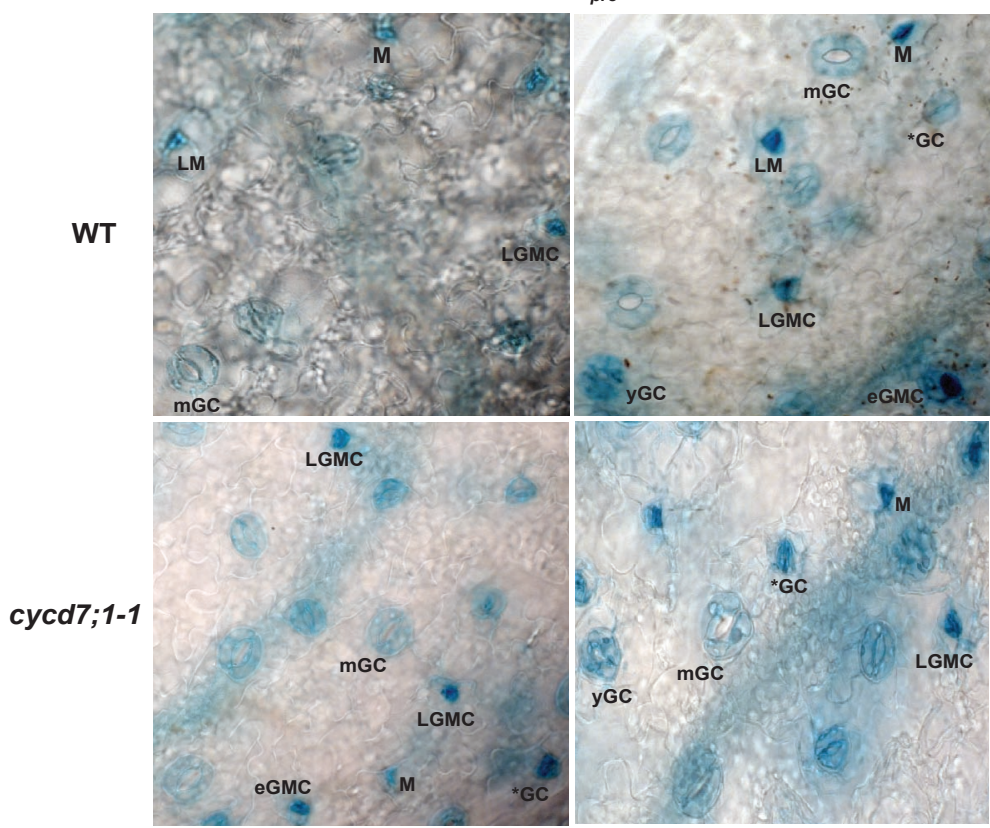

D

\begin{tabular}{llll}
\hline & Meristemoid & GMC & Stomata \\
4DAG & & & \\
WT & $163 \pm 20$ & $168 \pm 10$ & $227 \pm 14$ \\
cycd7; $1-1$ & $110 \pm 15$ & $132 \pm 16$ & $141 \pm 25$ \\
7DAG & & & \\
WT & $67 \pm 5$ & $101 \pm 13$ & $390 \pm 39$ \\
cycd7;1-1 & $103 \pm 4$ & $119 \pm 3$ & $376 \pm 9$ \\
10DAG & & & \\
WT & $47 \pm 7$ & $85 \pm 8$ & $634 \pm 40$ \\
cycd7;1-1 & $102 \pm 11$ & $118 \pm 14$ & $454 \pm 27$ \\
14DAG & & $11 \pm 7$ & $941 \pm 65$ \\
WT & $0 \pm 0$ & $16 \pm 6$ & $634 \pm 51$ \\
cycd7;1-1 & $7 \pm 4$ & & \\
\hline
\end{tabular}

C

cycd7;1-1 cycd7;1-1

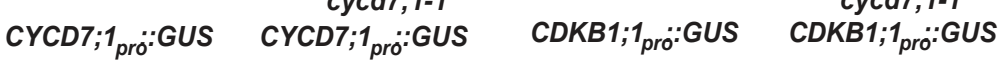

4DAG
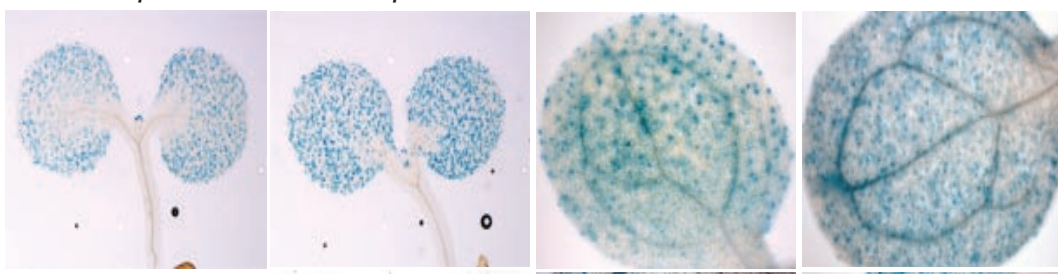

Figure 3

7DAG
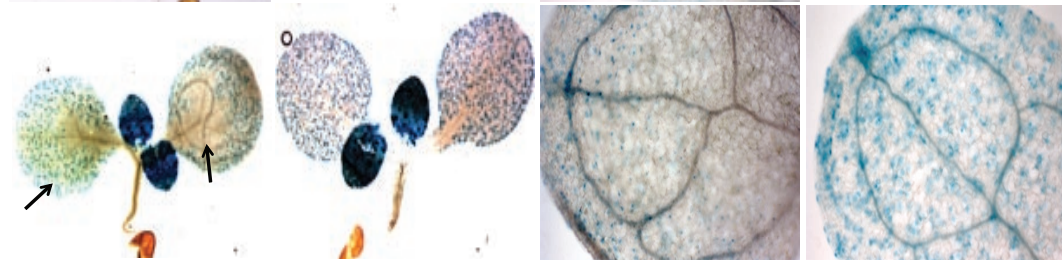

10DAG
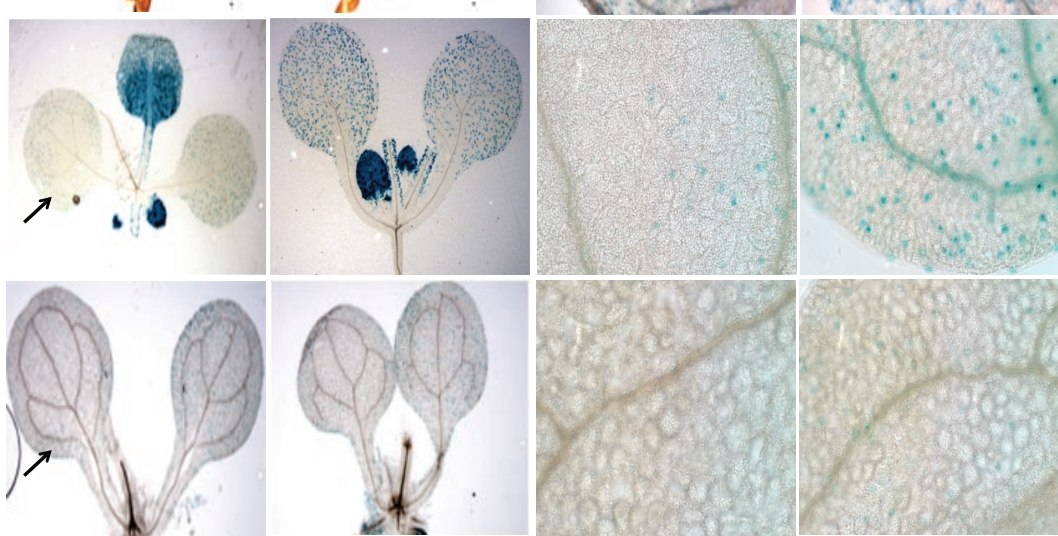
bioRxiv preprint doi: https://doi.org/10.1101/207845; this version posted October 23, 2017. The copyright holder for this preprint (which was not certified by peer review) is the author/funder, who has granted bioRxiv a license to display the preprint in perpetuity. It is made available under aCC-BY-NC-ND 4.0 International license.

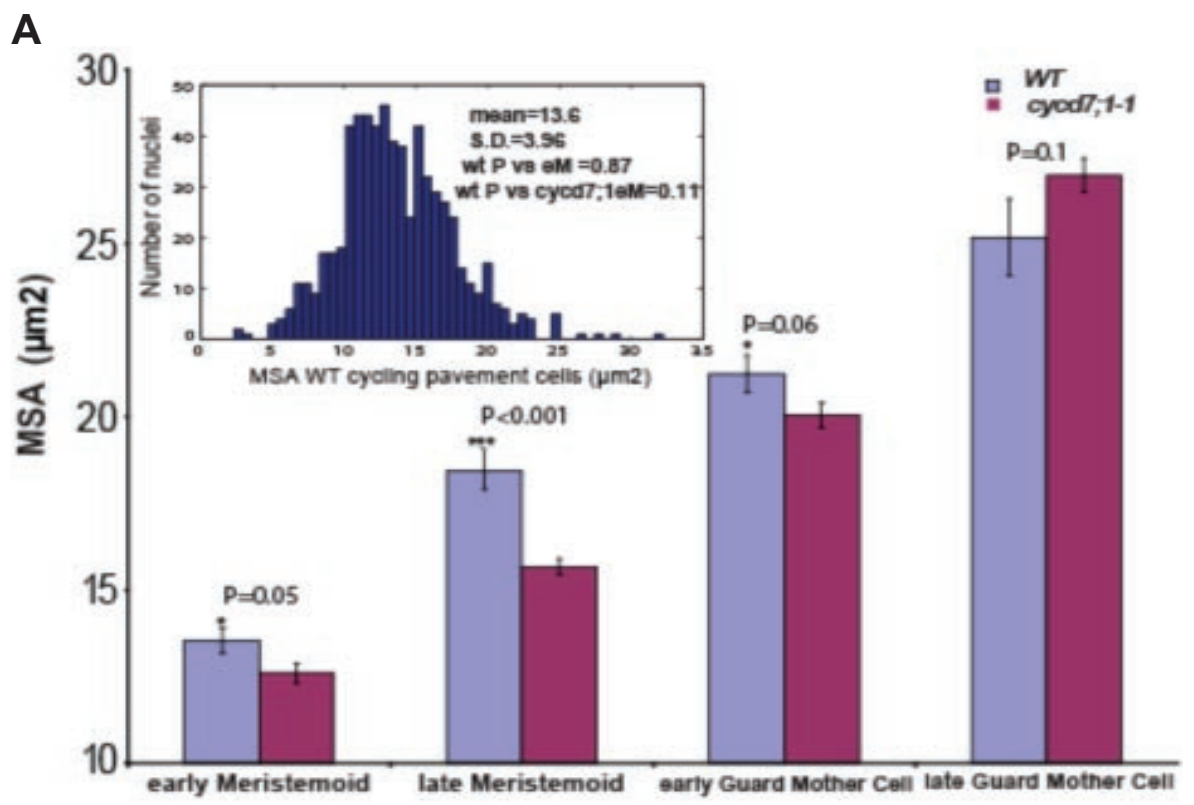

B

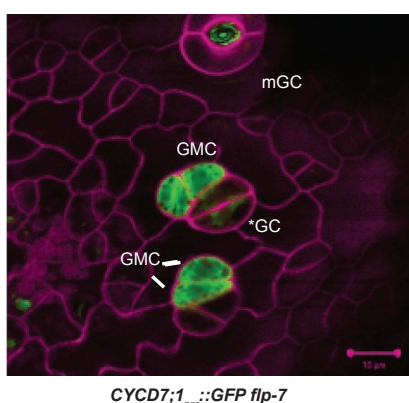

C

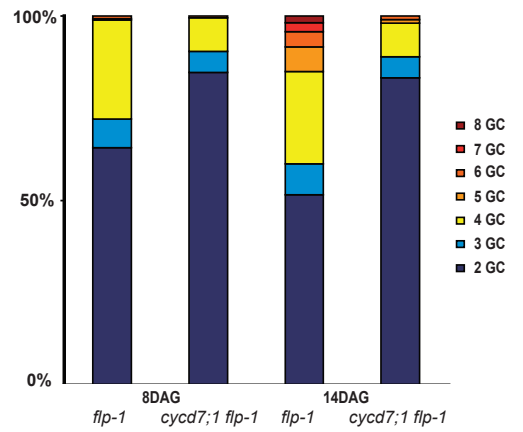

Figure 4 